\title{
Growth Inhibitory Activity of Selected Australian Syzygium Species against Malodour Forming Bacteria
}

\author{
Aiden Joshua Wood, ${ }^{a}$ Kane McManus, ${ }^{a}$ Mitchell Henry Wright, ${ }^{\mathrm{b}}$ Anthony Carlson Greene, ${ }^{\mathrm{a}}$ Ian Edwin Cock, ${ }^{\mathrm{a}, \mathrm{c}, *}$ \\ aSchool of Natural Sciences, Griffith University, Nathan Campus, Queensland, AUSTRALIA. \\ bDivision of Environmental and Biomolecular Systems, Institute of Environmental Health, Oregon Health \& Science University, Portland, Oregon, USA. \\ cEnvironmental Futures Research Institute, Griffith University, Nathan Campus, Queensland, AUSTRALIA.
}

\begin{abstract}
Background: Extracts produced from S. australe and S. luehmannii fruit and leaves are potent growth inhibitors of many bacterial pathogens. They may also inhibit the growth of malodour producing bacteria and thus be useful deodorant components, although this is yet to be tested. Methods: S. australe and S. luehmannii fruit and leaf solvent extracts were investigated by disc diffusion assays against significant bacterial contributors to axillary and plantar malodour formation. Toxicity was determined using the Artemia franciscana nauplii bioassay. Results: S. australe and S. Iuehmannii solvent extracts were good inhibitors of $B$. linens and $C$. jeikeium growth, with zones of inhibition up to $10 \mathrm{~mm}$ measured. S. australe extracts were generally better inhibitors of both bacterial species compared with the S. luehmannii extracts. Ethyl acetate extracts were particularly potent, with MIC values of 300 and $857 \mu \mathrm{g} / \mathrm{mL}$ for the $S$. australe fruit and leaf extracts respectively against $B$. linens, and 1000 and $311 \mu \mathrm{g} / \mathrm{mL}$ against C. jeikeium. The S. Iuehmannii fruit ethyl acetate extracts were similarly potent growth inhibitors, with MIC values of 571 and $203 \mu \mathrm{g} / \mathrm{mL}$ against B. linens and $C$. jeikeium respectively. $S$. australe aqueous and methanolic leaf extracts were also potent inhibitors of $C$. jeikeium (MIC's of 285 and $306 \mu \mathrm{g} / \mathrm{mL}$ respectively). All other extracts had moderate or low inhibitory
\end{abstract}

activity. All of the most potent ethyl acetate extracts were nontoxic in the Artemia franciscana bioassay. In contrast, the methanolic and aqueous S. australe leaf extracts, as well as the aqueous and methanolic S. luehmannil fruit extracts displayed apparent toxicity. However, these results may be fallacious and instead result from the high antioxidant content of these extracts. Conclusion: The potent growth inhibition of axillary and plantar malodour producing bacteria by the Syzygium spp. extracts indicate their potential as deodorant components.

Keywords: Body odour, Deodorant, Corynebacterium, Myrtaceae, Riberry, Brush cherry, High antioxidant, Medicinal plants.

\section{Correspondence:}

Dr. Ian Edwin Cock,

School of Natural Sciences,

Griffith University, Nathan Campus,

Queensland, AUSTRALIA.

Tel: +61 737357637 ;

E-mail: i.cock@griffith.edu.au

DOI: 10.5530/pc.2017.3.19

\section{INTRODUCTION}

Antiperspirants and deodorants are cosmetic products used to prevent and manage undesirable body odour and/or excessive sweating. Antiperspirants are designed to decrease sweat production, whereas deodorants inhibit the formation of body odour. Antiperspirants and deodorants are frequently combined and sold as a single product. These products are applied directly to the skin as aerosols, roll-ons, in a powdered form or as a gel. These products are used by over $90 \%$ of adult consumers in the United States and are one of the most widely used cosmetic products globally. ${ }^{1}$ Sweating results in the production fats and other wastes which can serve as a nutrient source for natural bacterial flora. The undesirable odours associated with sweat production is a direct result of enzymatic breakdown of these compounds through bacterial interaction. ${ }^{2}$

Several well-known bacteria are associated with the production of noxious malodours, with the prevalence and distributions of these varying between different regions of the body. Three predominating genera of bacteria are responsible for malodour production within the axillary region of the body; Corynebacterium, Propionibacterium and Staphylococcus. ${ }^{3,4}$ Corynebacterium spp. are generally considered to be the major contributors to axillary odour. Malodour manifestation occurs through the metabolism of short branched chain fatty acids, sulfanylalkanols and steroidal compounds to produce malodorous volatile compounds. ${ }^{5}$ Similar processes occur in the foot region. However the major bacteria responsible for odour formation in this region belong to the genera Brevibacterium and Propionibacterium. ${ }^{6}$

Deodorants contain chemicals formulated to minimize growth of odour forming bacteria. The efficacy of these chemicals is dependent on the microbial community present. The chemicals may include triclosan, benzalkonium chloride, glycol or metal (especially aluminium) salts.? However, the potential health risks associated with several of these chemical additives are poorly studied and in some instances they have been linked with serious health issues. Some antiperspirant and deodorant components may induce a range of negative side effects including respiratory problems, anaphylactic shock and degenerative neurological disorders (encephalopathy and Alzheimer's disease). ${ }^{8}$ There are also concerns of chronic toxicity associated with prolonged exposure to triclosan, as well as allergies and dermal irritation, although the concentrations required are not typically present in deodorants. ${ }^{8}$ The antibacterial properties of numerous plants have long been recognized by many cultures and may be alternatives to chemically-formulated deodorants.

Syzygium is a large genus of evergreen flowering plants (family Myrtaceae) consisting of approximately 500 species. ${ }^{9}$ Various species occur throughout the tropical and subtropical regions of South-East Asia, Australia and Africa. Many species produce edible fruits and berries with high antioxidant contents. In the commercially most important species Syzygium aromaticum (clove), the unopened flower bud is used as a spice. This plant also has uses in traditional medicine as an anaesthetic and for its antibacterial activity. ${ }^{10}$ Numerous studies have reported on the ability of $S$. aromaticum oils to inhibit the growth of panels of bacteria ${ }^{11}$ and fungi. ${ }^{12}$ Indian species (Syzygium lineare and Syzygium cumini), ${ }^{9}$ South East Asian species (Syzygium jambos), ${ }^{13}$ and African species (Syzygium cordatum $)^{14,15}$ also have potent antimicrobial activity. In contrast, much of our knowledge about the antiseptic properties of Australian Syzygium spp. is anecdotal, although Australian Aborigines are known to have used some species as medicinal agents. ${ }^{9,16}$

Despite their reported therapeutic uses, most recent interest in the Australian Syzygium spp. has focused on their high antioxidant capacities ${ }^{17}$ and the potential correlation between antioxidants and chronic disease. ${ }^{18}$ High antioxidant levels have also been shown to act as a preventative 
against the development of some degenerative diseases including cancer, ${ }^{19}$ cardiovascular diseases,${ }^{28}$ neural degeneration, ${ }^{21}$ diabetes and obesity. ${ }^{22}$ Furthermore, recent studies have also reported antibacterial activity in extracts from several other high antioxidant Australian plants. ${ }^{23-26}$ Particularly noteworthy, the bacterial growth inhibitory properties of several Australia Syzygium spp. have been reported against a broad panel of bacteria. ${ }^{16,27,28}$ In particular, high antioxidant Syzygium australe (J.C.Wendl. Ex Link) B. Hyland (bush cherry) and Syzygium luehmannii (F.Muell.) L.A.S.Johnson (riberry) extracts have been highlighted as potent bacterial growth inhibitors. ${ }^{9,16}$ Despite the reported broad spectrum antibacterial activity of $S$. australe and $S$. luehmannii extracts, they are yet to be evaluated for their ability to inhibit the growth of odour forming bacteria. The current study was undertaken to test the ability of $S$. australe and S. luehmannii fruit and leaf extracts to inhibit the growth of bacteria associated with axillary and plantar malodour formation.

\section{MATERIALS AND METHODS}

\section{Plant source and extraction}

Syzygium australe (J.C.Wendl. Ex Link) B. Hyland and Syzygium luehmannii (F.Muell.) L.A.S. Johnson fruit and leaves were collected from verified trees in suburban regions of Brisbane, Australia. Voucher samples of plant specimens are deposited at the School of Natural Sciences, Griffith University. The materials were comprehensively desiccated in a Sunbeam food dehydrator and the dried materials were stored at $-30^{\circ} \mathrm{C}$. Prior to usage, the materials were thawed and ground into a coarse powder. Individual $1 \mathrm{~g}$ masses of the material were then weighed into separate tubes and $50 \mathrm{~mL}$ of deionised water, methanol, chloroform, hexane or ethyl acetate were added. All solvents used were analytical-reagent grade and were obtained from Ajax Chemicals, Australia. The ground plant materials were separately extracted in each solvent for 24 hours at $4^{\circ} \mathrm{C}$ with gentle shaking. The extracts were subsequently filtered through Whatman No. 54 filter paper under vacuum, followed by drying by rotary evaporation in an Eppendorf concentrator 5301. The resultant dried extracts were weighed and suspended in $10 \mathrm{~mL}$ sterilized deionised water containing $1 \%$ DMSO.

\section{Qualitative phytochemical studies}

Phytochemical analysis of the extracts was completed as previously described ${ }^{29,30}$ and used to determine the presence of phenolic compounds, anthraquinones, phytosterols, cardiac glycosides, tannins, saponins, flavonoids, alkaloids, and triterpenoids.

\section{Antioxidant capacity}

The antioxidant capacity of each sample was assessed using a modified DPPH free radical scavenging method. ${ }^{31}$ Ascorbic acid ( $0-25 \mu$ g per well) was used as a reference and the absorbances were measured and recorded at $515 \mathrm{~nm}$. All tests were completed alongside controls on each plate and all were performed in triplicate. The antioxidant capacity based on DPPH free radical scavenging ability was determined for each extract and expressed as $\mu \mathrm{g}$ ascorbic acid equivalents per gram of original plant material extracted.

\section{Antibacterial screening \\ Test bacterial strains}

All media and components was supplied by Oxoid Ltd., Australia. Reference strains of Brevibacterium linens (ATCC 9172) and Corynebacterium jeikeium (ATCC 43734) were acquired from American Type Culture Collection, USA. To culture the bacteria, $B$. linens were inoculated into separate flasks of nutrient broth and grown aerobically at $37^{\circ} \mathrm{C}$ for $24 \mathrm{~h}$. Cultures of $C$. jeikeium were grown and maintained in nutrient broth supplemented with $300 \mu \mathrm{L}$ Tween $80 / \mathrm{L}$ of broth at $37^{\circ} \mathrm{C}$ for $24 \mathrm{~h}$. All stock cultures were subcultured and maintained in liquid media at $4^{\circ} \mathrm{C}$.

\section{Evaluation of antibacterial activity}

Antibacterial activity screening of the $S$. australe and S. luehmannii extracts was assessed using a modified disc diffusion assay [32, 33]. Briefly, $100 \mu \mathrm{L}$ of each individual isolate was grown separately in $20 \mathrm{~mL}$ of the appropriate broth until an approximate count of $10^{8}$ cells $/ \mathrm{mL}$ was reached. A volume of $100 \mu \mathrm{L}$ of each bacterial suspension was spread onto nutrient agar plates and the extracts were tested for antibacterial activity using $6 \mathrm{~mm}$ sterilised filter paper discs. B. linens cultures was spread onto nutrient agar plates and $C$. jeikeium cultures onto nutrient agar plates supplemented with $300 \mu \mathrm{L}$ Tween $80 / \mathrm{L}$ of agar. Discs were infused with $10 \mu \mathrm{L}$ of the individual extracts, allowed to dry and placed onto the inoculated plates. The plates were left to stand at $4{ }^{\circ} \mathrm{C}$ for $2 \mathrm{~h}$ before incubation. Plates inoculated with $B$. linens or C. jeikeium cultures were incubated aerobically at $37^{\circ} \mathrm{C}$ for $24 \mathrm{~h}$. The diameters of the inhibition zones were measured to the closest whole millimetre. Each assay was completed in at least triplicate. Mean values $( \pm$ SEM) are reported in this study. Vancomycin $(5 \mu \mathrm{g})$ discs were obtained from Oxoid Ltd., Australia and used as positive controls to compare antibacterial activity. Filter discs infused with $10 \mu \mathrm{L}$ of distilled water were used as a negative control.

\section{Minimum inhibitory concentration (MIC) determination}

The minimum inhibitory concentrations (MIC) of each plant extract was determined as previously described. ${ }^{34,35}$ Briefly, each individual plant extract was diluted in deionised water and tested across a decreasing concentration gradient. Discs were impregnated with $10 \mu \mathrm{L}$ of the extract dilutions, allowed to dry and placed onto plates inoculated with $B$. linens or C. jeikeium. The assay was performed in triplicate as outlined above and graphs of the zone of inhibition versus concentration were plotted. Linear ln regression was utilized to determine MIC values.

\section{Toxicity screening \\ Reference toxin for toxicity screening}

Potassium dichromate $\left(\mathrm{K}_{2} \mathrm{Cr}_{2} \mathrm{O}_{7}\right)$ (AR grade, Chem-Supply, Australia) was prepared in sterilized deionized water $(4 \mathrm{mg} / \mathrm{mL})$ and serially diluted in artificial seawater for use in the Artemia franciscana nauplii bioassay.

\section{Artemia franciscana nauplii toxicity screening}

Toxicity of all extracts were determined using an adapted Artemia franciscana nauplii lethality assay ${ }^{36,37}$ Briefly, $400 \mu \mathrm{L}$ of seawater containing $\sim 43$ (mean 43.2, $\mathrm{n}=155, \mathrm{SD} 14.5$ ) A. franciscana nauplii were added to wells of a 48 well plate and immediately used in the bioassay. Volumes of $400 \mu \mathrm{L}$ of reference toxin or the diluted plant extracts were transferred to the wells and incubated at $25 \pm 1{ }^{\circ} \mathrm{C}$ under artificial light (1000 Lux). Negative controls ( $400 \mu \mathrm{L}$ seawater) and all test treatments were run in triplicate for each plate. The wells were observed at regular intervals and the number of dead were counted. The nauplii were classified as dead if no movement was detected within 10 seconds. After $24 \mathrm{~h}$, all nauplii were sacrificed and counted to determine the total \% mortality per well. The $\mathrm{LC}_{50}$ with $95 \%$ confidence limits for each treatment was determined using probit analysis.

\section{Statistical analysis}

Data is expressed as the mean \pm SEM of at least three independent experiments. 
Table 1: The mass of dried extracted material, the concentration after resuspension in deionised water, qualitative phytochemical screenings and antioxidant capacities of the Syzygium spp. extracts.

\begin{tabular}{|c|c|c|c|c|c|c|c|c|c|c|c|c|c|c|c|c|c|}
\hline$\frac{\overrightarrow{\frac{\pi}{\pi}}}{\frac{0}{\alpha}}$ & 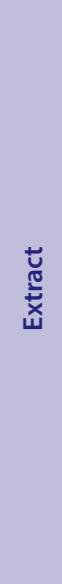 & 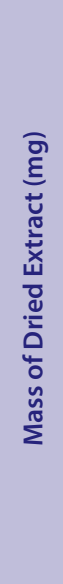 & 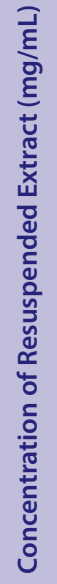 & 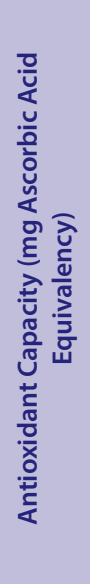 & $\begin{array}{l}\frac{\tilde{c}}{\overline{0}} \\
\frac{\bar{c}}{0} \\
\frac{\tilde{c}}{0} \\
\frac{\pi}{0} \\
\stackrel{0}{0}\end{array}$ & 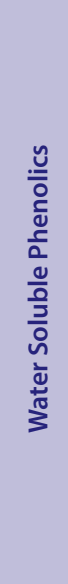 & 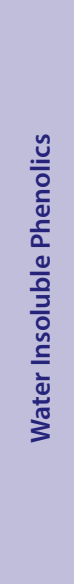 & 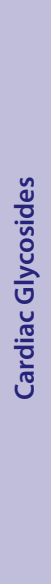 & 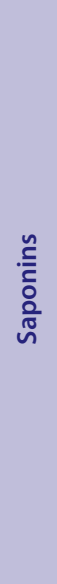 & 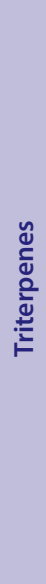 & 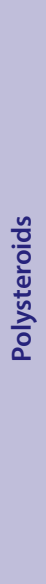 & 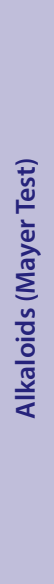 & 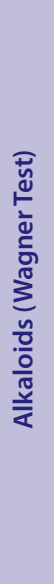 & $\begin{array}{l}\text { 믐 } \\
0 \\
\frac{0}{0} \\
\frac{\pi}{4}\end{array}$ & 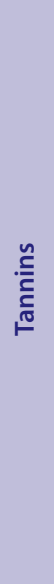 & 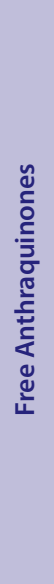 & 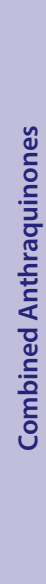 \\
\hline \multirow{6}{*}{ 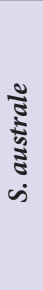 } & FW & 240 & 24 & 40.7 & +++ & +++ & ++ & - & + & - & - & - & - & +++ & + & - & - \\
\hline & FM & 360 & 36 & 55.2 & +++ & +++ & +++ & - & - & + & - & - & - & +++ & + & - & - \\
\hline & FE & 110 & 11 & 9.2 & ++ & - & ++ & - & - & - & - & - & - & + & - & - & - \\
\hline & LW & 180 & 18 & 25.3 & +++ & +++ & ++ & - & + & + & - & - & - & ++ & + & - & - \\
\hline & LM & 360 & 36 & 40.2 & +++ & +++ & +++ & - & + & + & - & - & - & +++ & + & - & - \\
\hline & LE & 110 & 11 & 2.58 & ++ & - & ++ & - & - & - & - & - & - & ++ & - & - & - \\
\hline \multirow{3}{*}{ 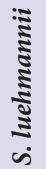 } & FW & 120 & 12 & 59.2 & +++ & +++ & ++ & - & + & + & - & - & - & +++ & + & - & - \\
\hline & FM & 560 & 56 & 94.6 & +++ & +++ & +++ & - & + & + & - & - & - & +++ & + & - & - \\
\hline & FE & 130 & 13 & 1.5 & ++ & - & ++ & - & - & - & - & - & - & + & - & - & - \\
\hline
\end{tabular}

+ indicates a minor response; ++ indicates a moderate response; +++ indicates a major response. $\mathrm{FW}=$ aqueous fruit extract; $\mathrm{FM}=$ methanolic fruit extract; $\mathrm{FE}=$ ethyl acetate fruit extract; $\mathrm{LW}=$ aqueous leaf extract; $\mathrm{LM}=$ methanolic leaf extract; $\mathrm{LE}=$ ethyl acetate leaf extract. Antioxidant capacity was determined by DPPH reduction and is expressed as mg ascorbic acid equivalents per $\mathrm{g}$ of original plant material extracted.

\section{RESULTS}

\section{Liquid extraction yields and qualitative phytochemical screening}

Extraction of the dried Syzygium spp. fruit and leaf materials (1 g) with various solvents yielded dried plant extracts ranging from $110 \mathrm{mg}$ to $360 \mathrm{mg}$ (S. australe fruit and leaf extracts) and $120 \mathrm{mg}$ to $560 \mathrm{mg}$ (S. luehmannii fruit extracts) (Table 1). Methanolic extracts provided significantly greater yields of extracted material relative to the aqueous and ethyl acetate counterparts, which provided only low to moderate yields. The dried extracts were resuspended in $10 \mathrm{~mL}$ of deionised water (containing $1 \%$ DMSO), resulting in the concentrations presented in Table 1.

\section{Antioxidant content}

Antioxidant capacity for the plant extracts (Table 1) ranged from $1.5 \mathrm{mg}$ (S. luehmannii fruit ethyl acetate extract) to a high of $55.2 \mathrm{mg}$ ascorbic acid equivalence per gram of dried plant material extracted (S. australe fruit methanolic extract). The antioxidant capacities for the aqueous and methanolic extracts of each plant part were generally similar for both species and were substantially higher than the corresponding ethyl acetate extracts.

\section{Antimicrobial activity Brevibacterium linens}

B. linens growth was inhibited by all of the Syzygium spp. extracts screened (100\%) (Figure 1$)$. The S. australe extracts were generally more potent inhibitors of growth than the $S$. luehmannii extracts (as judged by zone of inhibition), with inhibition zones as high as $9.0 \pm 0.6 \mathrm{~mm}$ (S. australe leaf methanolic extract). This compares favourably with the vancomycin $(5 \mu \mathrm{g})$ control, with an inhibitory zone of $12.3 \pm 0.6 \mathrm{~mm}$. Indeed, all Syzygium spp. fruit and leaf extracts displayed inhibition zones $\geq 7 \mathrm{~mm}$ except for the aqueous $S$. luehmannii fruit extract.

\section{Corynebacterium jeikeium}

Bacterial growth was inhibited by 8 of 9 extracts screened (89\%) (Figure 1). The $S$. australe extracts were again the more potent inhibitors of bacterial growth than were the $S$. luehmannii extracts (as judged by zone of inhibition), with inhibitory zones as large as $10.0 \pm 0.6 \mathrm{~mm}$ (S. australe fruit aqueous extract) and $9.6 \pm 0.3 \mathrm{~mm}$ (S. australe fruit methanolic extract). In contrast, $S$. luehmannii extracts were less effective at inhibiting C. jeikeium growth, with smaller zones of inhibition of $6.3 \pm 0.3 \mathrm{~mm}$ (S. luehmannii fruit methanolic extract) and $8.0 \pm 1.2 \mathrm{~mm}$ (S. luehmannii fruit ethyl acetate extract) respectively.

\section{Minimal inhibitory concentration determinations}

The antimicrobial efficacy of the extracts was further quantified through the determination of MIC values (Table 2). The ethyl acetate fruit and 


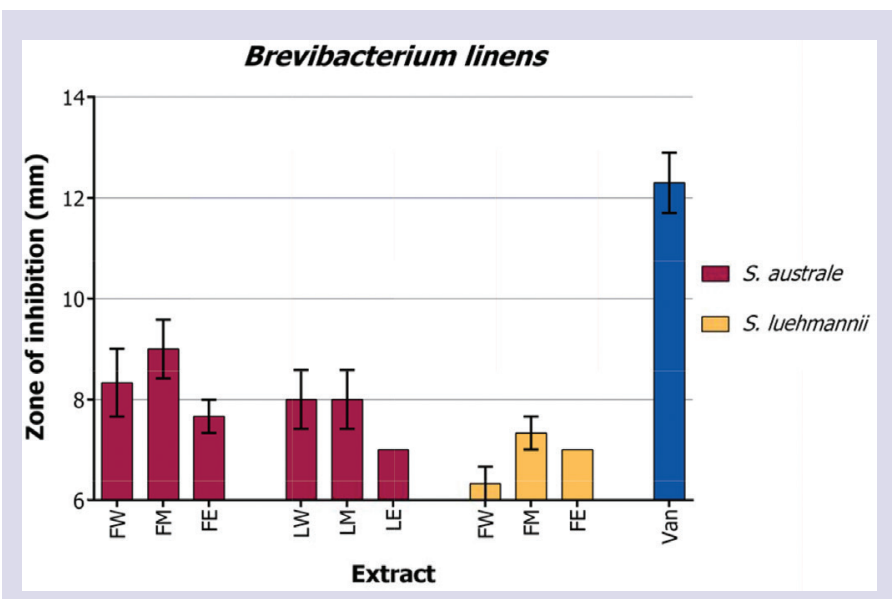

Figure 1: Growth inhibitory activity of Syzygium spp. plant extracts against the $B$. linens isolate measured as zones of inhibition $(\mathrm{mm})$. $\mathrm{FW}=$ aqueous fruit extract; $\mathrm{FM}=$ methanolic fruit extract; $\mathrm{FE}=$ ethyl acetate fruit extract; $L W=$ aqueous leaf extract; $L M=$ methanolic leaf extract; $\mathrm{LE}=$ ethyl acetate leaf extract; $V a n=$ vancomycin $(5 \mu \mathrm{g})$. Results are expressed as mean zones of inhibition \pm SEM.

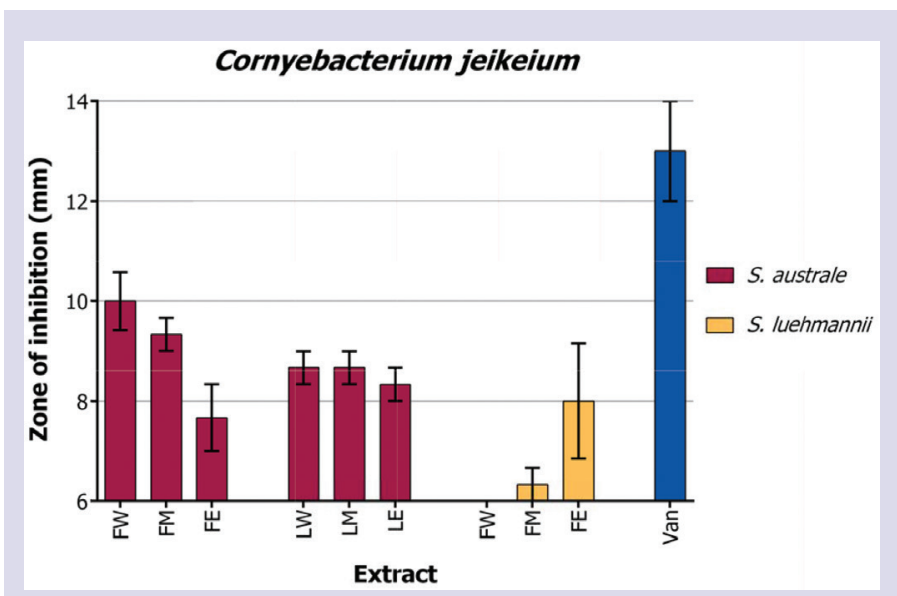

Figure 2: Growth inhibitory activity of Syzygium spp. plant extracts against the $C$. jeikeium isolate measured as zones of inhibition $(\mathrm{mm})$. $\mathrm{FW}=$ aqueous fruit extract; $\mathrm{FM}=$ methanolic fruit extract; $\mathrm{FE}=$ ethyl acetate fruit extract; $L W=$ aqueous leaf extract; $L M=$ methanolic leaf extract; $L E=$ ethyl acetate leaf extract; $\operatorname{Van}=$ vancomycin $(5 \mu \mathrm{g})$. Results are expressed as mean zones of inhibition $\pm \mathrm{SEM}$.

leaf extracts of both Syzygium spp. were particularly effective at inhibiting B. linens and C. jeikeium growth, with MIC values generally substantially $<1000 \mu \mathrm{g} / \mathrm{mL}(<10 \mu \mathrm{g}$ infused into the disc). Similarly, the aqueous and methanolic $S$. australe leaf extracts were also good bacterial growth inhibitors, particularly against C. jeikeium, with MIC values of 285 and $306 \mu \mathrm{g} / \mathrm{mL}$ respectively ( $3 \mu \mathrm{g}$ infused into the disc). These results compare well with the growth inhibitory activity of the vancomycin controls which were tested at $5 \mu \mathrm{g}$. All other extracts were of moderate or low efficacy in the assay.

\section{Quantification of toxicity}

The extracts were initially screened in the Artemia nauplii lethality assay at $2000 \mu \mathrm{g} / \mathrm{mL}$ (Figure 3). Potassium dichromate was used as a reference
Table 2: Minimum inhibitory concentration $(\mu \mathrm{g} / \mathrm{mL})$ of the Syzygium spp. extracts against $B$. linens, $C$. jeikeium and $\mathrm{LC}_{50}$ values $(\mu \mathrm{g} / \mathrm{mL})$ in the Artemia nauplii bioassay.

\begin{tabular}{|c|c|c|c|c|}
\hline $\begin{array}{l}\frac{\vec{c}}{\frac{\pi}{a}} \\
\frac{1}{a}\end{array}$ & 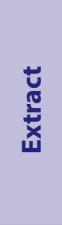 & 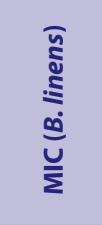 & 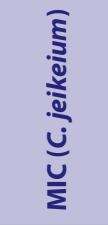 & $u^{\text {in }}$ \\
\hline \multirow{6}{*}{ 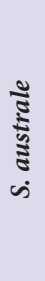 } & FW & 1,286 & 1,760 & 3,310 \\
\hline & FM & 3,852 & 4,545 & 1,879 \\
\hline & FE & 300 & 1,000 & - \\
\hline & LW & 1,067 & 285 & 244 \\
\hline & LM & 1,486 & 306 & 294 \\
\hline & LE & 857 & 311 & - \\
\hline \multirow{3}{*}{ 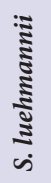 } & FW & $>10,000$ & - & 478 \\
\hline & FM & $>10,000$ & $>10,000$ & 414 \\
\hline & FE & 571 & 203 & - \\
\hline \multirow{2}{*}{$\begin{array}{l}\frac{n}{0} \\
0 \\
0 \\
0\end{array}$} & PC & ND & ND & 186 \\
\hline & SW & ND & ND & - \\
\hline
\end{tabular}

Numbers indicate the mean MIC and $\mathrm{LC}_{50}$ values of triplicate determinations. - indicates no inhibition. $\mathrm{FW}=$ aqueous fruit extract; $\mathrm{FM}=$ methanolic fruit extract; $\mathrm{FE}=$ ethyl acetate fruit extract; $\mathrm{LW}=$ aqueous leaf extract; $\mathrm{LM}=$ methanolic leaf extract; $\mathrm{LE}=$ ethyl acetate leaf extract; $\mathrm{PC}$ = potassium dichromate control; $\mathrm{SW}=$ negative (seawater) control. $\mathrm{ND}=$ the indicated test was not performed.

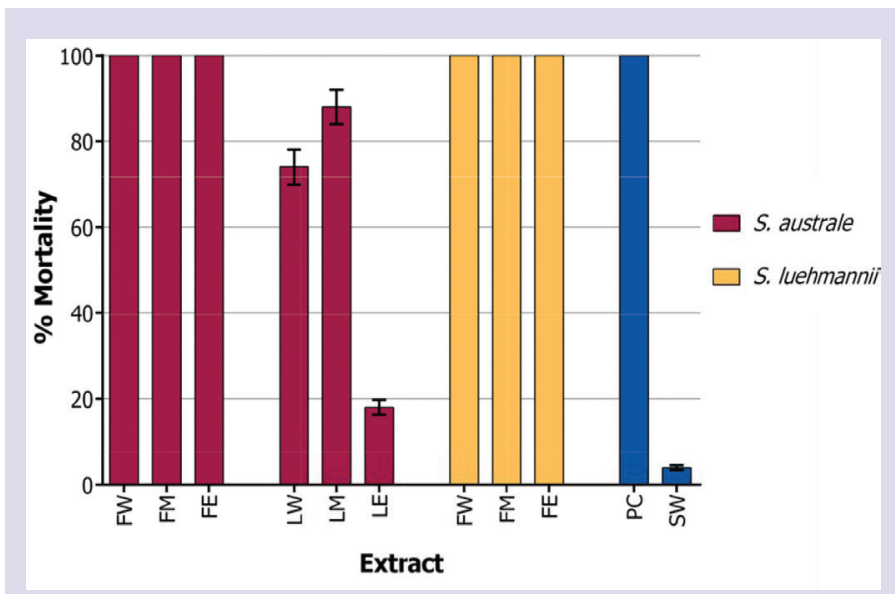

Figure 3: The lethality of the Australian plant extracts $(2000 \mu \mathrm{g} / \mathrm{mL})$ and the potassium dichromate $(1000 \mu \mathrm{g} / \mathrm{mL})$ and seawater controls towards Artemia franciscana nauplii after 24 hours exposure. $\mathrm{FW}=$ aqueous fruit extract; $F M=$ methanolic fruit extract; $F E$ = ethyl acetate fruit extract; LW $=$ aqueous leaf extract; $L M=$ methanolic leaf extract; $L E=$ ethyl acetate leaf extract; $\mathrm{PC}=$ potassium dichromate control; $\mathrm{SW}=$ negative (seawater) control. Results are expressed as mean $\%$ mortality \pm SEM.

toxin in the bioassay and was rapid in its onset of mortality, inducing nauplii death within the first $3 \mathrm{~h}$ of exposure and $100 \%$ mortality was evident within 4-5 h (unpublished results). With the exception of the ethyl acetate leaf extracts of both species, all extracts showed $>50 \%$ mortality rates at $24 \mathrm{~h}$ (Figure 3). To further quantify the effects of toxin concentration on Artemia nauplii mortality, the extracts were serially 
diluted in artificial seawater to test across a series of concentrations in the Artemia nauplii bioassay. The $24 \mathrm{~h} \mathrm{LC}_{50}$ values of the Syzygium spp. extracts towards $A$. franciscana are presented in Table 2. No $\mathrm{LC}_{50}$ values are reported for the fruit or leaf ethyl acetate extracts of either species as $<50 \%$ mortality was seen in all tested concentrations. Extracts with an $\mathrm{LC}_{50}>1000 \mu \mathrm{g} / \mathrm{ml}$ towards Artemia nauplii have been defined as being nontoxic. ${ }^{38}$ The $S$. australe fruit methanolic and aqueous extracts both also had $\mathrm{LC}_{50}$ values substantially $>1000 \mu \mathrm{g} / \mathrm{mL}$ and were therefore deemed to be non-toxic. The methanolic and aqueous extracts of $S$. australe leaf and of S. luehmannii fruit displayed $\mathrm{LC}_{50}$ values substantially $<1000$ $\mu \mathrm{g} / \mathrm{mL}$ and were therefore considered to be toxic. This was a surprising result as $S$. australe and $S$. luehmannii fruit are considered nutritious, high antioxidant foods. However, it is noteworthy that the bioassay organism (Artemia franciscana) is sensitive to extreme $\mathrm{pH}$ ranges. Our study reported that all the extracts with $\mathrm{LC}_{50}$ values $<1000 \mu \mathrm{g} / \mathrm{mL}$ had relatively high antioxidant capacities. Furthermore, previous studies ${ }^{35}$ reported that the high antioxidant capacities of these Syzygium spp. is largely due to their high ascorbic acid contents. Therefore, it is likely that the apparent toxicity reported in this study may be fallacious and a result of the extracts high ascorbic acid contents.

\section{DISCUSSION}

Body malodour (encompassing both axillary and foot odour) is directly related to the production and content of an individual's sweat. Sweating provides fats and nutrients which provide ideal growth conditions for many bacteria. Corynebacterium spp. possess enzymes to degrade protein and lipid sweat components to produce strongly malodorous volatile components. ${ }^{39}$ Staphylococcus spp. possess similar (albeit less active) enzymes and are therefore capable of producing similar volatile compounds and thus also contribute to axillary malodour. ${ }^{39}$ Brevibacterium spp. and Propionibacterium spp. (and to a lesser extent, Corynebacterium spp. and Staphylococcus spp.) are the main bacteria responsible for foot malodour production..$^{40}$ Current deodorant compositions seek to control axillary and plantar malodour in several ways:

- Inhibition/reduction of the bacteria which cause axillary and/or plantar malodours. Triclosan is currently the most common bacterial growth inhibitor in commercial deodorants. However, chronic triclosan exposure has been linked to a myriad of serious health problems. ${ }^{41}$ Furthermore, triclosan persists for a relatively short period and is rapidly inactivated. ${ }^{42}$ Therefore, there is a need to develop more effective antimicrobial deodorant components and recent studies have examined plant extracts for this purpose. ${ }^{4}$

- Antiperspirants reduce sweating, usually by mechanical obstruction of eccrine sweat ducts. ${ }^{43}$ Aluminium salts are the most commonly used compound in antiperspirant formulations. However, there are concerns about chronic exposure to these chemicals and even acute exposure has been linked with a wide range of negative health effects including degenerative neurological conditions (e.g. Alzheimer's disease, encephalopathy ${ }^{44}$ and cancer. ${ }^{45}$

- Masking the malodour with other, more palatable aromas.

Due to the health concerns associated with some of the current antiperspirant/deodorant components, the development of safer formulations is required. These products are used at least daily and often more frequently by large section of the population. Thus the potential for chronic and additive effects on deodorant compounds need to be taken into account when formulating new products. Formulating products with greater functionality would allow for lower doses and thus lower health risks. The antibacterial compound triclosan is present in some products at up to $1 \%$ of the formulation (although $0.1-0.15 \%$ is more common). ${ }^{46}$ Triclosan is readily absorbed through the skin and conjugated forms have been reported to persist in the plasma for several days. ${ }^{47}$ Indeed, the time required to clear $50 \%$ of a single triclosan dose in humans has been reported to be 96 h. ${ }^{48}$ As deodorants are applied frequently and often as repeated applications, the implications and possibility for systemic accumulation and chronic toxicity are obvious.

There is a need to develop safer, more effective new deodorant compositions which address these concerns. Antibacterial plant formulations are ideal candidates for potential deodorant compounds. Plant extracts and oils have been used in a variety of traditional healing systems to inhibit the growth of bacterial pathogens. In many case their efficacy has been verified by rigorous scientific examination against those bacteria. It is possible that some of these may also inhibit the growth of malodour forming bacteria. Furthermore, natural components are desirable as deodorants as they may be more acceptable to consumers due to their natural origin and consumer perception of safety. This study examined the growth inhibitory properties of a $S$. australe and S. luehmannii leaf and fruit extracts against two of the major bacterial species associated with axillary and plantar malodour formation. S. australe and S. luehmannii were selected for this study for several reasons. These species have been used by the first Australians as antiseptics for thousands of years. ${ }^{16}$ Throughout this long history of use, there has been a complete lack of toxicity reporting, attesting to the safety of these products for both consumption and topical application. Furthermore, recent laboratory studies have reported potent growth inhibitory activity for $S$. australe and S. luehmannii fruit. ${ }^{27,35,49}$ and leaf extracts ${ }^{35,50}$ against extensive microbial panels. The same studies also reported low toxicity for all extracts, further supporting their safety.

Our study confirmed the potential of $S$. australe and S. luehmannii fruit and leaf extracts for inhibiting the growth of axillary and foot malodour producing bacteria. The $S$. australe ethyl acetate leaf and fruit extracts and the S. luehmannii ethyl acetate fruit extract were the most promising growth inhibitors against both bacterial species. As Corynebacterium spp. have been reported to produce the most unpleasant and strongest malodours, ${ }^{4}$ the potent inhibition of $C$. jeikeium by these extracts was particularly encouraging. Despite Corynebacterium spp. being the most significant contributors to body malodour formation, the inhibitory activity against $S$. epidermidis has been most extensively reported. Extracts produced from the Asian medicinal and edible plant Caesalpinia mimosoides were reported to be inhibitors of S. epidermidis growth with an MIC value of $3130 \mathrm{ppm}$ (equivalent to $3130 \mu \mathrm{g} / \mathrm{mL}$ ). ${ }^{51}$ Similarly, Cassia alata ${ }^{52}$, Barleria lupulina and Psidium guajava ${ }^{53}$ were moderate inhibitors of $S$. epidermidis growth, with MIC values equivalent to $2500-5000 \mu \mathrm{g} / \mathrm{mL}$. Hibiscus sabdariffa and Eupatorium odoratum were reported to be potent $S$. epidermidis growth inhibitors, each with MICs equivalent to $625 \mu \mathrm{g} / \mathrm{mL} . .^{53}$ On the basis of its $S$. epidermidis growth inhibitory properties, a $H$. sabdariffa deodorant formulation was the basis for a US patent application. ${ }^{54}$

Examination of the growth inhibition of other malodour producing bacteria by herbal formulations has been less extensively reported. Rubia tinctorum (commonly known as madder) crude extracts were reported to be strong inhibitors of Corynebacterium xerosis growth. ${ }^{55}$ However, that study is of limited value as a single, high dose of the extract was screened (approximately $500 \mu \mathrm{g} /$ disc). Furthermore, MIC values were not determined, making a comparison with other studies impossible. Similarly, Anethum graveolens essential oils inhibited Corynebacterium spp. Growth. ${ }^{56}$ However, MIC values were not reported within this study, making a comparison difficult. Furthermore, that study utilised a disc diffusion assay to test the growth inhibitory activity of the oil. Whilst disc diffusion assays are suited to the study of extracts, they are not recommended when testing oils for antibacterial activity due to the insolubility of the oils in the aqueous gel matrix. Another study reported potent inhibition of C. xerosis and S. epidermidis growth by a supercritical Humulus 
lupulus (commonly known as hops) extract. ${ }^{57}$ The authors reported $15 \mathrm{~mm}$ zones of inhibition for a $2 \mathrm{mg} / \mathrm{mL}$ H. lupulus extract using a disc diffusion assay. It is difficult to compare the MIC quantification results reported in that study to those in our study due to the use of different assay methods. However, a direct comparison of the disc diffusion studies is possible. Our study screened substantially lower doses in the disc diffusion assay compared to the H. lupulus study, yet recorded similar inhibition zones. Thus, it is likely that the potency of the methanolic $S$. australe aqueous, methanolic and ethyl acetate leaf extracts and the ethyl acetate S. luehmannii extract compare favourably with the $H$. lupulus extract.

This study focussed on the antibacterial deodorant properties of the S. australe and S. luehmannii extracts. However, other biological properties not examined in our study may also provide further protection against malodour production. Products that inhibit perspiration would also limit the secretion of the protein and lipid sweat components required as energy sources for bacterial growth. Thus, if these extracts were subsequently found to also have antiperspirant activity (in conjunction with the deodorant activity), they may be especially useful for a deodorant formulation as they would have dual functions.

The majority of the Syzygium spp. extracts examined in our study displayed significant toxicity $(<1000 \mu \mathrm{g} / \mathrm{mL})$ in the Artemia nauplii bioassay. Indeed, the aqueous and methanolic $S$. australe leaf extracts and the aqueous and methanolic $S$. luehmannii fruit extracts had $\mathrm{LC}_{50}$ values $<500 \mu \mathrm{g} / \mathrm{mL}$, indicating moderate to high toxicity. This toxicity would impact on the usefulness of these extracts as deodorant additives. Similar extracts prepared using these species have previously been reported to have high ascorbic acid levels in other studies. ${ }^{17}$ Whilst these ascorbic acid levels may have beneficial therapeutic effects, they may also be responsible (at least in part) for the toxicity reported here. Whilst A. franciscana have generally been reported to be a robust and hardy organism for toxicity screening, they are susceptible to $\mathrm{pH}$ changes. ${ }^{58}$ The levels of ascorbic acid previously reported in S. australe and S. luehmannii extracts ${ }^{17}$ would be expected to have a significant impact on the $\mathrm{pH}$ of the seawater in the tests and this change may be responsible for the mortality induction reported in our study. Indeed, studies in our laboratory have shown that testing pure ascorbic acid in the concentrations previously reported to be in these extracts results in mortality similar to that reported in our study (unpublished results). Pharmacodynamics and pharmacokinetics studies are also required to determine the ability of the extract components to cross the skin barrier, their duration in the blood stream prior to clearance, and the urinary excretory products. As deodorants are applied frequently, such studies are required for any formulation to ensure that their components do not accumulate and cause chronic toxicity.

\section{CONCLUSIONS}

The results of this study demonstrate the potential of the $S$. australe and $S$. luehmannii methanolic leaf extracts as a natural antibacterial components for deodorant formulation. These extracts were potent growth inhibitors of the major malodour forming bacterial species B. linens and C. jeikeium.

\section{REFERENCES}

1. Benohanian, A. Antiperspirants and deodorants. Clinics in Dermatology 2001 19(4): 398-405

2. Shelley WB, Hurley HJ, Nicholas AC. Axillary odor: experimental study of the role of bacteria, apocrine sweat, and deodorants. Archives of Dermatology and Syphilology 1953; 68: 430-446.

3. Grice EA, Kong HH, Conlan $\mathrm{S}$, et al. Topographical and temporal diversity of the human skin microbiome. Science 2009; 324(5931): 1190-1192.

4. McManus K, Wood A, Wright MH, et al. Terminalia ferdinandiana Exell. extracts inhibit the growth of body odour forming bacteria. International Journal of Cosmetic Science 2017. DOI: 10.1111/ics.12403
5. James AG, Casey J, Hyliands D, et al. Fatty acid metabolism by cutaneous bacteria and its role in axillary malodour. World Journal of Microbiology and Biotechnology 2004; 20(8): 787-793.

6. Kanlayavattanakul M, Lourith N. Body malodours and their topical treatment agents. International Journal of Cosmetic Science 2011; 33: 298-311.

7. Exley C. Does antiperspirant use increase the risk of aluminium-related disease, including Alzheimer's disease? Molecular Medicine Today 1998; 4(3): 107-109.

8. Bhargava HN, Leonard PA. Triclosan: applications and safety. American Journal of Infection Control 1996; 24(3): 209-218.

9. Cock IE, Cheesman MJ. A review of the ethnobotany, medicinal properties and phytochemistry of plants of the genus Syzygium (Myrtaceae). In Innovations in Agriculture and Biological Engineering, (in press). Eds. Gogal MR, Ayeleso A; Apple Academic Press, New York.

10. Cai L, Wu CD. Compounds from Syzygium aromaticum possessing growth inhibitory activity against oral pathogens. Journal of Natural Products 1996; 59: 987-990.

11. Arora DS, Kaur GJ. Antibacterial activity of some Indian medicinal plants. Journal of Natural Medicine 2007; 61: 313-317.

12. Park MJ, Gwak KS, Yang I, et al. Antifungal activities of the essential oils of Syzygium aromaticum (L.) Mer. Et Perry and Leptospermum petersonii Bailey and their constituents against various dermatophytes. Journal of Microbiology 2007; 45 (5): 460-465.

13. Mohanty S, Cock IE. Bioactivity of Syzygium jambos methanolic extracts: Antibacterial activity and toxicity. Pharmacognosy Research 2010; 2(1): 4-9. DOI: 10.4103/0974-8490.60577

14. Cock IE, van Vuuren SF. Anti-Proteus activity of some South African medicinal plants: their potential for the prevention of rheumkatoid arthritis. Inflammopharmacology 2014; 22(1): 23-36. DOI: 10.1007/s10787-013-0179-3

15. Cock IE, van Vuuren SF. The potential of selected South African plants with antiKlebsiella activity for the treatment and prevention of ankylosing spondylitis Inflammopharmacology 2015; 23(1): 21-35. DOI: 10.1007/s10787-014-0222-z

16. Cock IE. Medicinal and aromatic plants - Australia. In Ethnopharmacology section, Biological, Physiological and Health Sciences. Encyclopedia of Life Support Systems (EOLSS) 2011; Developed under the auspices of the UNESCO: EOLSS Publishers, Oxford, UK (http://www.eolss.net).

17. Netzel M, Netzel G, Tian Q, et al. Native Australian fruits - a novel source of antioxidants for food. Innovative Food Science and Emerging Technologies 2007; 8: 339-346

18. Jamieson N, Sirdaarta J, Cock IE. The anti-proliferative properties of Australian plants with high antioxidant capacities against cancer cell lines. Pharmacognosy Communications 2014; 4(4): 71-82. DOI: 10.5530/pc.2014.4.8

19. Hertog MG, Bueno-de-Mesquita HB, Fehily AM, et al. Fruit and vegetable consumption and cancer mortality in the caerphilly study. Cancer Epidemiology Biomarkers and Prevention 1996; 5: 673-677.

20. Vita JA. Polyphenols and cardiovascular disease: Effects on endothelial and platelet function. American Journal of Clinical Nutrition 2005; 81(1): 292S-297S

21. Youdim KA, Spencer JPE, Schroeter $H$, et al. Dietary flavonoids as potential neuroprotectants. Biological Chemistry 2002; 383: 503-519.

22. Tsuda T, Horio F, Uchida K, et al. Dietary cyanidin 3-O-b- D-glucoside-rich purple corn colour prevents obesity and ameliorates hyperglycemia in mice. Journal of Nutrition 2003; 133: 2125-2130.

23. Sirdaarta J, Matthews B, White A, et al. GC-MS and LC-MS analysis of Kakadu plum fruit extracts displaying inhibitory activity against microbial triggers of multiple sclerosis. Pharmacognosy Communications 2015; 5(2): 100-115. DOI: 10.5530/pc.2015.2.2

24. Sirdaarta J, Matthews B, Cock IE. Kakadu plum fruit extracts inhibit growth of the bacterial triggers of rheumatoid arthritis: Identification of stilbene and tannin components. Journal of Functional Foods 2015; 17: 610-620. DOI: 10.1016/j. jff.2015.06.019

25. Winnett $\mathrm{V}$, Boyer $\mathrm{H}$, Sirdaarta J, et al. The potential of Tasmannia lanceolata as a natural preservative and medicinal agent: antimicrobial activity and toxicity. Pharmacognosy Communications 2014; 4(1): 42-52. DOI: 10.5530/ pc.2014.1.7

26. Cock IE, Mohanty S. Evaluation of the antibacterial activity and toxicity of Terminalia ferdinandiana fruit extracts. Pharmacognosy Journal 2011; 3(2): 72-79. DOI: 10.5530/pj.2011.20.14

27. Sautron C, Cock IE. Antimicrobial activity and toxicity of Syzygium australe and Syzygium luehmannii fruit extracts. Pharmacognosy Communications 2014; 4(1): 53-60. DOI: 10.5530/pc.2014.1.8

28. Chikowe G, Mpala L, Cock IE. Antibacterial activity of selected Australian Syzygium species. Pharmacognosy Communications 2013; 3(4): 77-83.

29. Wright MH, Courtney R, Greene AC, et al. Growth inhibitory activity of Indian Terminalia spp. against the zoonotic bacterium Bacillus anthracis. Pharmacognosy Journal 2016; 6(1): 2-9. DOI: 10.5530/pc.2016.1.2

30. Wright $\mathrm{MH}$, Sirdaarta J, White $\mathrm{A}$, et al. Bacillus anthracis growth inhibitory properties of Australian Terminalia spp.: Putative identification of low polarity volatile components by GC-MS headspace analysis. Pharmacognosy Journal. 2016; 8(3): 281-90. DOI: 10.5530/pj.2016.3.18 
31. Wright MH, Sirdaarta J, Matthews B, et al. Growth inhibitory activity of Kakadu Plum extracts against the opportunistic pathogen Clostridium perfringens: New leads in the prevention and treatment of Clostridial myonecrosis. Pharmacognosy Journal 2016; 8(2): 144-53. DOI: 10.5530/pj.2016.2.8

32. Wright MH, Arnold MSJ, Lee CJ, et al. Qualitative phytochemical analysis and antibacterial activity evaluation of Indian Terminalia spp. against the pharyngitis causing pathogen Streptococcus pyogenes. Pharmacognosy Communications 2016; 6(2): 85-92. DOI: 10.5530/pc.2016.2.6

33. Lee CJ, Wright MH, Arnold MSJ, et al. Inhibition of Streptococcus pyogenes growth by native Australian plants: New approaches towards the management of impetigo, pharyngitis and rheumatic heart disease. Pharmacognosy Communications 2016; 6(3): 164-73. DOI: 10.5530/pc.2016.3.6

34. Wright $\mathrm{MH}$, Greene $\mathrm{AC}$, Cock IE. Inhibition of Bacillus anthracis growth by Australian native plants used traditionally as antibacterial medicines. Pharmacognosy Journal 2015; 7(6): 389-96. DOI: 10.5530/pj.2015.6.13

35. Wright $\mathrm{MH}$, Lee CJ, Pollock CE, et al. Growth inhibitory activity of selected high antioxidant Australian Syzygium species against the food poisoning and tissue necrotic pathogen Clostridium perfringens. Pharmacognosy Communications 2016; 6(2): 93-9. DOI: 10.5530/pc.2016.2.7

36. Wright MH, Sirdaarta J, White A, et al. GC-MS headspace analysis of Terminalia ferdinandiana fruit and leaf extracts which inhibit Bacillus anthracis growth. Pharmacognosy Journal 2017; 9(1): 73-82. DOI: 10.5530/pj.2017.1.14

37. Wright $\mathrm{MH}$, Arnold MSJ, Aldosary $\mathrm{H}$, et al. Bioactive constituents of Terminalia ferdinandiana Exell: A pharmacognistic approach towards the prevention and treatment of yersiniosis. Pharmacognosy Communications. 2016; 6(3): 152-63. DOI: $10.5530 / p c .2016 .3 .5$

38. Ruebhart D, Wickramasinghe W, Cock IE. Protective efficacy of the antioxidants vitamin E and Trolox against Microcystis aeruginosa, microcystin-LR and menadione toxicity in Artemia franciscana nauplii. Journal of Toxicology and Environmental Health Part A 2009; 72(24): 1567-1575. DOI: 10.1080/15287390903232459

39. Shelley WB, Hurley HJ, Nicholas AC. Axillary odor: experimental study of the role of bacteria, apocrine sweat, and deodorants. Archives of Dermatology and Syphilology 1953; 68: 430-446.

40. Kanlayavattanakul M, Lourith N. Body malodours and their topical treatment agents. International Journal of Cosmetic Science 2011; 33: 298-311.

41. Bhargava HN, Leonard PA. Triclosan: applications and safety. American Journal of Infection Control 1996; 24(3): 209-218.

42. Nakae T, Gomyo H, Sasaki I, Kimoto Y,Hanzawa N, Teshima Y, Namba T. New antiaxillary odour deodorant made with antimicrobial Ag-zeolite (silver-exchanged zeolite). International Journal of Cosmetic Science 2006; 28: 200-309.

43. Behohanian A. Antiperspirants and deodorants. Clinics in Dermatology 2001; 19(4): 398-405.
44. Exley C. Does antiperspirant use increase the risk of aluminium-related disease, including Alzheimer's disease? Molecular Medicine Today 1998; 4(3): 107-109.

45. Darbre PD, Pugazhendi D, Mannello F. Aluminium and human breast diseases Journal of Inorganic Biochemistry 2011; 105: 1484-1488.

46. Jones RD, Jampani HB, Newman JL, Lee AS. Triclosan: A review of effectiveness and safety in health care settings. American Journal of Infection Control 2000; 28(2): 184-196.

47. Krishnan K, Gagné M, Nong A, Aylward LL, Hays SM. Biomonitoring equivalents of triclosan. Regulatory Toxicology and Pharmacology 2010; 58(1); 10-17.

48. Sandborgh-Englund G, Adolfsson-Erici M, Odham G, Ekstrand J. Pharmacokinetics of triclosan following oral ingestion in humans. Journal of Toxicology and Environmental Health Part A 2006; 69: 1861-1873.

49. Maen A, Cock IE. Inhibitory activity of high antioxidant Australian native fruits against the bacterial triggers of selected autoimmune diseases. Pharmacognosy Communications 2015; 5(1): 48-59.

50. Cock IE. Antimicrobial activity of Syzygium australe and Syzygium luehmanni leaf methanolic extracts. Pharmacognosy Communications 2012; 2(2): 71-77. DOI: $10.5530 / p c .2012 .2 .11$

51. Chanwitheesuk A, Teerawutgulrag A, Kilburn JD, Rakariyatham N. Antimicrobial gallic acid from Caesalpinia mimosoides Lamk. Food Chemistry 2007; 100(3): 1044-1048.

52. Yadav JP, Arya V, Yadav S, Panghal M, Kumar S, Dhankhar S. Cassia occidentalis L.: a review on its ethnobotany, phytochemical and pharmacological profile. Fitoterapia 2010; 81(4): 223-230.

53. Chomnawang MT, Surassmo S, Wongsariya K, Bunyapraphatsara N. Antibacterial activity of Thai medicinal plants against methicillin-resistant Staphylococcus aureus. Fitoterapia 2009; 80(2): 102-104.

54. Bockmuhl D, Hohne HM, Jassoy C, Schollyssek R, Waldmann-Laue M, Scholz W, Sattler A. Probiotically active plant extracts. US patent 11/336, 164; 2006.

55. Golcü, A, Dolaz M, Dıgrak M, Serin S. The biological activity of dyer's madder (Rubia tinctorium L.). In $1^{\text {st }}$ International Congress of the Chemistry of Natural Products 2002; 255-258.

56. Singh G, Kapoor IP, Pandey SK, Singh UK, Singh RK. Studies on essential oils: part 10; antibacterial activity of volatile oils of some spices. Phytotherapy Research 2002; 16(7): 680-682.

57. Dumas ER, Michaud AE, Bergeron C, LaFrance JL, Mortillo S, Gafner S Deodorant effects of a supercritical hops extract: antibacterial activity against Corynebacterium xerosis and Staphylococcus epidermidis and efficacy testing of a hops/zinc ricinoleate stick in humans through the sensory evaluation of axillary deodorancy. Journal of Cosmetic Dermatology 2009; 8(3): 197-204.

58. Cock IE, Ruebhart DR. Comparison of the brine shrimp nauplii bioassay and the ToxScreen-II test for the detection of toxicity associated with Aloe vera (Aloe barbadensis Miller) leaf extract. Pharmacognosy Research 2009; 1(2): 98-101.

\section{PICTORIAL ABSTRACT}

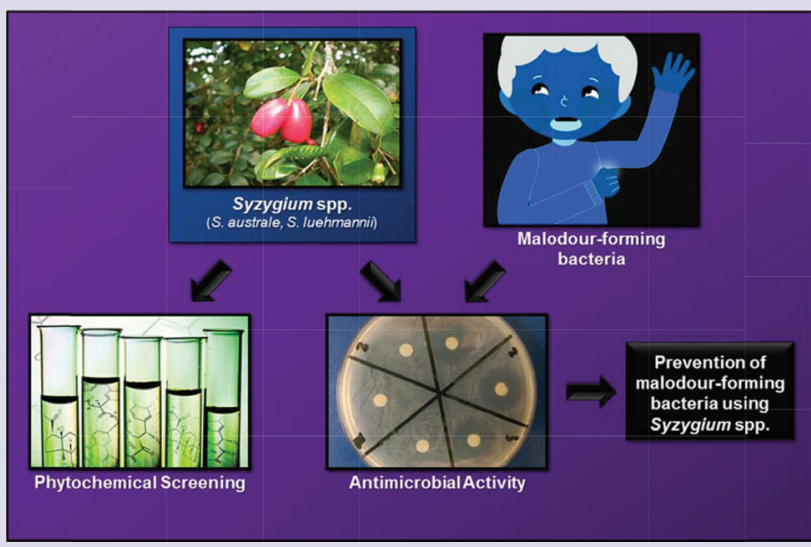

\section{SUMMARY}

- $\quad$ Ethyl acetate $S$. australe leaf and fruit and S. luehmannii fruit extracts were potent inhibitors of $B$. linens and $C$. jeikeium growth.

- $\quad \mathrm{MIC}$ values of 300 and $1000 \mu \mathrm{g} / \mathrm{mL}$ were determined for $S$. australe fruit ethyl acetate extract against $B$. linens and $C$. jeikeium respectively.

- $\quad$ Ethyl acetate extracts of $S$. australe leaf $(857$ and $311 \mu \mathrm{g} / \mathrm{mL}$ against B. linens and C. jeikeium respectively) and S. luehmannii fruit (571 and $203 \mu \mathrm{g} / \mathrm{mL}$ against $B$. linens and $C$. jeikeium) were similarly potent.

- S. australe aqueous and methanolic leaf extracts were also potent inhibitors of C. jeikeium (MIC's of 285 and $306 \mu \mathrm{g} / \mathrm{mL}$ respectively).

- All other extracts had moderate or low inhibitory activity.

- All ethyl acetate extracts were nontoxic in the Artemia franciscana bioassay

\section{ABOUT AUTHORS}

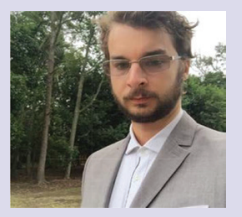

Mr. Aiden Wood completed his Biomolecular Science (Hons.) degree at the end of 2015. His thesis was investigated the potential application of Crispr/Cas9 to model inherited forms of Parkinson's disease. Currently he is investigating the antibacterial potential of Australian native plants traditionally used in Aboriginal medicine. He is proficient in a wide range of molecular and microbial techniques. 


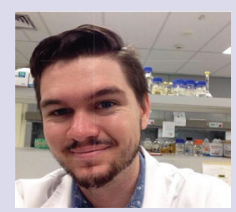

Mr Kane McManus obtained his Bachelor of Science with Honours in 2015 for his work investigating bacterial-metal interactions of contaminated suburban creeks. Since completing this project, his research has largely focused on the commercial aspects of native Australian plants, specifically the utilization of natural antibacterial agents in the prevention of malodour-forming bacteria. Kane is currently working within the medical field while he assesses his Ph.D. options both domestically and abroad.

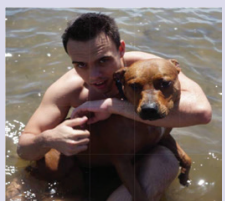

Dr. Mitchell Henry Wright is a postdoctoral researcher at Oregon Health \& Science University in Portland, Oregon (USA) where he investigates $\mathrm{Mn}(\mathrm{III})$ transformations in aquatic systems. Specifically, his research focuses on manganese oxidation/reduction by bacteria and how these organisms influence the geochemical cycling of the metal. His previous postdoctoral posting involved investigating the potential of Australian native plants in the treatment and prevention of various pathogenic bacteria. This has resulted in several publications between both disciplines.

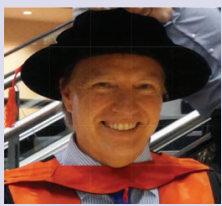

Dr. Anthony Carlson Greene is a senior lecturer and researcher at Griffith University, Brisbane Australia. He obtained his $\mathrm{PhD}$ in Microbiology from the University of New South Wales and focuses on extreme environments, bioremediation and geomicrobiology. His specific interests include the microbial ecology of thermophilic, saline and alkaliphilic environments and the mechanisms and industrial potential of extremophilic bacteria contained therein.

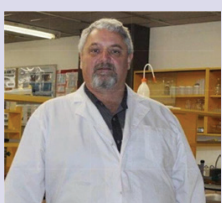

Dr lan Edwin Cock leads a research team in the Environmental Futures Research Institute and the School of Natural Sciences at Griffith University, Australia. His research involves bioactivity and phytochemical studies into a variety of plant species of both Australian and international origin, including Aloe vera, South Asian and South American tropical fruits, as well as Australia plants including Scaevola spinescens, Pittosporum phylliraeoides, Terminalia ferdinandiana (Kakadu plum), Australian Acacias, Syzygiums, Petalostigmas and Xanthorrhoea johnsonii (grass trees). This range of projects has resulted in nearly 200 scientific publications in a variety of peer reviewed journals. 